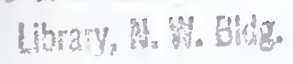

U. S. DEPARTMENT OF COMMERCE

NOV 161949

NATIONAL BUREAU OF STANDARDS

CENTRAL RADIO PROPAGATION LABORATORY

W ASHINGTON, D. C.

AVERAGE RADIO RAY REFRACTION

IN THE LOWER ATMOSPHERE

BY M. SCHULKIN 
Report No. CRPL-2-2

\section{AVERAGE RADIO RAY REFRACTION IN THE LOWER ATHOSPHERE**}

by

M. Schulkin

\section{Abstrect:}

The average refractive bending of radio-frequency rays has been calculated from actual radio-frequency refractive index distributions with height as computed from mean radiosonde data. The maximum possible bending occurs for rays passing entirely through the atmosphere and arriving or departing tangentially at the earth's surface. The range of this total angular ray bending extends from 11 milliradians (mr) $\left(0.63^{\circ}\right)$ at Falrbenks, Alaska, in April, to $18 \mathrm{mr}\left(1.01^{\circ}\right)$ at San Juan, Puerto Rico, in Juiy, and 18 about $14 \mathrm{mr}$ $\left(0.80^{\circ}\right)$ at Washington, D.C., in October. About $90 \%$ of the ray bending occurs in the lowest $10 \mathrm{~km}$ of the atmosphere. These results are compared with the ray bending computed from the $4 / 3$ offective earth's radius approximation.

\section{Table of Contents:}

Page

1. Introduction .................... 1

2. Atmosphoric Refraction of Radio Wares. . . . . . . 3

3. Meteorological Data and Refractive Index Computations. - 7

4. Computation of Refraction . . . . . . . . . . . 8

5. Conclusion .................... 11

Appendix 1: Estimate of Uncertainty in Application of Refractive Index Formula for Molst Air ....... 12

Appendix 2: Extrapolation of Refractive Index Data to $30 \mathrm{~km}$. 16

Appendix 3: Derivation of Formula for Refraction, $\tau$, of a Radio Ray ............... 17

Appendix 4: Applications of Formula for Refraction of a Rad1o Ray ..................

* This paper is the first part of a standard refraction study, the goel of which is the calculation of fleld intensity as affected by arerage refraction conditions when one or both of the terminals is very high, such as a high-flying aircraft or rocket. By the "lower tmosphere" is arbitrarily meant that portion of the atmosphere up to about $18 \mathrm{~km}$. However, an estimate $1 \mathrm{~s}$ made in this study of the contribution to the repraction of the atmosphere above this elevation, excluding any lonospheric effects. 


\section{Introduction}

The problem of radio-rey tracing is closely connected with the proble of astronomical refrection. The prinolphl difference betweon optical-ray and radio-ray sefraction is due to the offoct of the Iarge contribution of water vapor to the reiractire index of the atmosphere at radio Prequencies. The history of atmospheric optical-ray tracing is a long one and is mostly deroted to the computation of astronomical refraction and somewhat to geodetic survoying. Garfinkel(1) reviows the past history of astrononical refraction cllculations, and he presents a mothod of obtaining total optical refraction for a ray passing antirely through the earth's atmosphere for angles of elevation less than 100. In all the astronomical refraction investigation, the air density-height distribution function is approrimated by plausible physical models. Garfinkel fits mean sounding data to his model, which consists of a termperature lapse up to the stratosphere, and then an isothernal stratosphere. Ho show that his results agree quite vell, within the orror of measurement, with the secul-emplrical tables of Radav and Puikowa.

The tapulated sounding data which he used were teken fras Himphreys (2) and were ropresontative of four Furopean citles betwoen the jears 1900 and 1912. Since the date of GarPinkel's paper (Fobruary 1944), the United States Woather Buresu has published (Hy 1945) average of radiosondo dats taken for the most part from July 1939 to December 1943 for the Nopth American notwork of tations from Alaske to the Ceribbean See. (3) These data are used in the present computations.

(1) "An Investigation in the Theory of Aetrononical Refraction," by B. Garfinkel, Astronomical Journal, Vol. 50 , No. $8(2 / 44)$.

(2) "Phydes of the Air," by W. J. Huphregs, MoGraw-H111 (1929) pp. $54-56$.

(3) Wopper Air Arerage Values of Teaperature, Pressure, and Relative Hullity orer the United Staten and llask," by R. Ratnor, Climate and Crop Weather Dir., U.S.W.B., Washington, D.C. (5/45). 


\section{Atmospheric Refraction* of Radio Hares.}

The object of atmospheric radio wave refraction studies ususily 1. to find a convenient method of correcting the radio wave fleldintensity oquations for this offect. This Plnal stup has not been taken in this paper, but a method of obtalning the true refraction 1. presented in Soction 4, page 8 . A survey of existing methods 18 made herein in terms of refraction calculations, instead of fleld-intensity applications for which thoy wore orlginally doalgned, and it is how how widely divergent the results of the different methode are from the true refraction. We show that the problem is one of correcting for refraction at different bolghts in the atmosphere and for different seasons at different geographical locations. The most widely used method of approximation is ob telned by using an effective carth's radius oqual to $4 / 3$ the actual radius. We furnigh data to examine the adequacy of the $4 / 3$ earth's sadius approximation.

In the present paper, refraction has been computed from the actual refractive index tructure of the atmosphere as obtained from avorage neteorological date at the location in question. The assumption 1\% rade, as is urually done, that the atwosphere is horlzontally homogeneous over that location. Calculations have been made for different refractive index structures over different locations. The results have been plotted as the solid curves A, B, C in Flgire 1, page 8. Curves A, B, and C represent the acturl veriation of refraction with helght, computed by mothods presented in this papor, for Fairbanks, Alaska, in April, for Washington, D.C., In Octobor, and for San Juan, Puerto Rico, in Jwiy. Brolen curves $A^{\prime}, B^{\prime}$, and $C^{\prime}$ ropresent the approximations obtained by a mothod due to Pearcey (see below) using a $4 / 3$ eartb's radius factor up to the helght at which the refractive index becowes unity and considering no refraction beyond this point.

The earliest auccessful attack on the problen of correcting radio propagation analysis for atmospherfe rofraction was introduced bs Schelleng, Burrows, and Ferrell (4) when thoy introduced

- Refraction 10 defined here as the total bending of a rey over a path. The curvature at a polnt on a curve is dofined as the rete of change of the tangent direction per unit length of curve at that point, and is messured in torms of change of angle per unit length of path. For a circle, the curvature et any point 18 constant and is equal to the reciprocal of the radius. When the curvature is known along a ray, the refraction any be computed as the intogral of the ourvature over the path.

(4) "Ultre Short Wave Propagation," by J. C. Sohelleng, C. R. Burrour, and E. B. Perroll, Proc. I.R.B., Vol. 21, P. $427(3 / 33)$. 
the concept of effective earth's radius. They found that a factor of $4 / 3$ was satisfectory for ennual average conditions, up to $0.5 \mathrm{~km} \mathrm{as}$ deduced from Humphreys' (2) weather data. However, the correction thus introduced is only strictly correct for an atmosphere with inear refractive index gradient of $39 \times 10^{-6}$ units per $\mathrm{km}$, and thus cannot possibly hold beyond the height (approximately $10 \mathrm{~km}$ ) at which tine refractive index has reached the value of unity. In addition, the atmosphere has a non-linear refractive index gradient, and the true correction will vary with elevation and distance.

Eckart and Plendl (5) showed how to correct for atmospheric refraction for nearly horizontal rays by fitting the actual refractive index structure by means of two parabolas, one from the surface to $5 \mathrm{~km}$, and the other from 5 to $10 \mathrm{~km}$. Above that elevation they considered the refraction negligible. The mothod furnished satisfactory tables of corrections for a mean atmoaphere to $10 \mathrm{~km}$. To extend the corrections to greater heights or to different refractive index distributions as encountered in different geographical locations would require additional parabolic fits of data and extensive calculations.

Stickland $(6,7)$ attempted to correct radio fleld-intensity calculations for the variation of refraction with height. An empirical relation was found for the average atmospheric refractive index distribution in terms of the ratio $m$ of the ray radius of curvature at any helght $h$ in the atmosphere for nearly horizontal rays,

$$
\text { m }=2.5+1.0 \mathrm{~h}
$$

$\mathrm{h}$ being given in $\mathrm{km}$. Meteorological conditiong in the lowest kilometer are admittedly quite varieble, but the formula was considered valid to $10 \mathrm{~km}$, above which height the refraction was assumed to have ceased. It was then suggested that for computational purposes, an average ratio $\bar{m}$ be used between any two points close together at heights $h_{1}$ and $h_{2}, \bar{m}=2.5+0.5\left(h_{1}+h_{2}\right)$. When one point is near the ground, $h_{1} \cong 0$, and then we have:

(5) Die Uberwindung der Erdkrumung bei Ultrakurzwellon durch die Strahlenbrechung in der Atmosphare," by G. Fickart and $\mathrm{H}$. Plendl, Hochfreq. und Elektroakustik, Vol. 52, No. $2(8 / 38)$ pp.44-58.

(6) "The Effect of Atmospheric Refraction on the Propagation of Radio Waves," by A. C. Stickland, R.R.B./S. $10(3 / 43)$.

(7) The Dielectric Constant of Water Vapour and its Effects on the Propagation of Very Short Waves," by A. C. Stickland, R.R.B./S.2 $(5 / 42)$. 


$$
\overline{\mathrm{m}}=2.5+0.5 \mathrm{~h}
$$

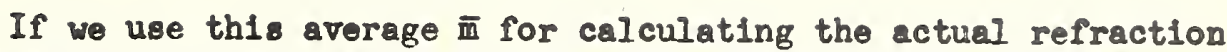
of a tangential ray, we get incorrect results. In order to demonstrate this, we will now proceed to work out the total refraction in terms of Stickland's average $m$ concept, and show that these values disagree with the true values of refraction as computed by the method outlined later on in this report. The stickland approxlmation calls for the use of a single average value of $\bar{m}$ between the ground and the helght $h$ and implies that we may use for this layer that value of effective earth's radius factor $\bar{k}$, related to $\bar{i}$ in equation 2 by:

(earth's curvature) - (ray curvature) = ("effectiven earth's curvature)

$$
\frac{1}{2}-\frac{1}{\mathrm{ma}}=\frac{1}{\mathrm{ka}}
$$

or: $\quad \overline{\mathrm{x}}=\frac{\overline{\mathrm{m}}}{\mathrm{In}=1}$

Now a general expression for the refraction $\tau$ for a tangential ray through a given layer of depth $h$, with an effective earth's radius factor $k$ corresponding to some linear gradient of refractive index 1.:

$$
\tau=\sqrt{\frac{2 h}{a}}\left(\sqrt{k}-\frac{1}{\sqrt{k}}\right) \quad \text { (See Appendix 4, page 20) }
$$

where: $\tau$ is the refraction in radians.

a is the earth' radius, expressed in the same units as $h$.

$h$ is the depth of the layer, measured from the ground.

$k$ is the effective earth's radiue factor.

The bending of a radio ray between the ground and helght $b, o b-$ tained from the last equation by using the values of $k$ obtained from equations (2) and (3) has been plotted in Figure 2, page 24, as Curve A. In this same figure we have also plotted: (I) Curve B, the actual refraction for a Stickland atmosphere defined by equation (I) and computed by the method presented in this report, (2) the mean refraction for Washington, D.C., in Ootober, and (3) the $4 / 3$ earth's radius approximation. It may be seen that the Stickland averaging process gives too low values of refraction, and that the simple $4 / 3$ earth's radius approximation is at least as satisfactory as Stickland'. refraction correction. The reason for the failure of Stickland's formula in this case is that the method of averaging $m$ has the effect of weighting all helght intervals equally, whereas the concept of the refraction as the integrated curvature along the ras path llowe for the condition that almost horizontal rays have much longer paths in the lower layers where the refraction 18 greatest. 
Pearcey ${ }^{(8)}$ has given a simplo arithmetical formulo (oquation 4 below) for correcting for the refraction of solar radio rays arriving at low angles $\theta_{0}$, a procedure necessary in solar noise studies, by using the surface value of the refractive index and then assuning a linear refractive index gradient of $39 \times 10^{-6}$ units/ke up to that helght at which the refractive index becomes unity. Above this height the refraction is considered to have ceased. This is equivalent to using a $4 / 3$ earth's radius factor but, in addition, the final height is specifled at which the correction is applicable. This model has the advantage of being simple and the validity of the approximation for total bending may be examined in the dashed curvesof Figure 1, page 23. Pearcey's formula for low ground angles of arrival or departure, $0 \leqslant \theta_{0} \leqslant 10^{\circ}$ is given by:

$$
\tau=\frac{\Delta n_{0}}{\left(\frac{n_{2}}{a}-\Delta n_{0}\right)}\left[\sqrt{2\left(\frac{h_{2}}{a}-\Delta n_{0}\right)+\theta_{0}^{2}}-\theta_{0}\right] \text { In radians }
$$

where: $\tau$ is the total bending in radians.

$\Delta n_{0}$ is $\left(n_{0}-1\right)$ where $n_{0}$ is the value of the refractive index at the earth's surface.

$h_{2}$ is the elevation at which $\Delta \mathrm{n}$ becones zero under a standard refractive index gradient of $39 \times 10^{-6}$ units/km.

2 is the earth's radius, expressed in the same units as $\mathrm{h}_{2}$.

From Figures 1 and 2, it may be seen that the refraction approdmations in use at the present time are not quite adequate for all seasons, geographical locations or at very high altitudes. However, the effect on field-intensity calculations of the deviations of the refraction approximations from the true refraction has not been determined in this gtudy. It is contemplated to study these effects and to present the results in a subsequent paper. It is also intended to use the recelvers of existing radar installations to get an experimental measure of the total atmospheric refraction of radio-frequency nolse from the sun at one or two frequencles between $100 \mathrm{Mc} / \mathrm{s}$ and $10,000 \mathrm{Mc} / \mathrm{s}$ for comparison with the refraction computed from nearly simultaneous meteorological soundings.

(8) "Solar Radiation at Radio Frequencies and its Relation to Sunspots," by J. L. Parsey, R. Payne Scott, L. L. McCready, R.P.R. $24(6 / 46)$ Commonwealth of Australia, Council for Scientific and Industrial Research, Division of Radiophysics. 


\section{Meteorological Data and Refractive Index Computations.}

The formula for the radio-frequency* refractive index of moist air is $(9)$ :

$$
(n-1) \times 10^{6}=\frac{79 p}{T}\left(1+4800 \frac{0}{p T}\right)
$$

Bquation (5) may be written in the forms

$(\mathrm{D}-1) \times 10^{6}=\frac{\frac{\text { Optical and Radio }}{\text { Requencr Term }}}{79 \mathrm{p} / \mathrm{T}}+\frac{\frac{\text { Bsplicit Water Vapor Term }}{\text { Required only Rt Radio Frequencies }}}{3.79 \times 10^{4} / \mathrm{T}^{2}}$

where: $n$ is the refractive index.

p 1s the total pressure in millibars (mb) and is equal to

$\mathrm{Pd}+\cdots$.

$P_{d}$ is the partial pressure of dry air.

- is the water vapor pressure.

$T$ is the temperature in $\mathrm{OK}$, and is equal to $273+t^{\circ} \mathrm{C}$.

This is a semi-ampirical formula and was obtained as a result of radio wave propagation studies and laboratory measurements of the rePractive index of water vapor and dry air. The adequacy of equation (5) as a basis for refraction calculations is discussed in Appendix I, page 12. Charts besed on this formula have been constructed for obtaining the refractive index of moist air at radio frequencies from moteorological data to helghts of $25 \mathrm{~km}$. In this report, representative radiosonde data published by the U.S. Weather Bureau $(3)$ have been used for the calculation of the refractive index distribution for three North American stations separated widely in geographical location for one month of each season. The computations were made by

* The formula is applicable for frequencies at least up to $30,000 \mathrm{Mc} / \mathrm{s}$. Although some variation of refraction might be expected to exist near various absorption 1 ines associated with various elements in the atmosphere, Van Vleck $(10)$ has pointed out that the observed magnitude of the absorption coefficient of oxygen and water vapor in the atmosphere whose absorption IInes Iie below $30,000 \mathrm{Mc} / \mathrm{s}$ would not be expected to be accompanied by appreciable changes in refrection. Further investigation may show that formula 5 is applicable at frequencles oven considerably in excess of $30,000 \mathrm{Mc} / \mathrm{s}$.

(9) "Nomograms for Computation of Modifled Index of Refraction," by R. A. Burgoyne, M.I.T. RI \#55I (4/45).

(10) Whe Relation between Absorption and the Frequency Dependence of Refraction," bs J. B. Van Viock, M.I.T. RL \#735 (5/45) 
drawing graphs respectively for the contribution due to the total pressure term, $79 \mathrm{p} / \mathrm{T}$, important both at optical and radio rrequepoles, and that due to the explicit water vapor pressure tern, $3.79 \times 10^{4} \mathrm{~d} / \mathrm{T}^{2}$, important only at radio frequencies. Flgures 3-6, pages 25-28 give the contribution of the total pressure tern to the refractive Index computation. P1gures 7 and 8, pages 29-30, give, in terne of relative humidity $(R R)$ and femperatare, the contribution due to the expllclt water vapor term (Relat1ve Humid1ty-Teaperature Term). The relation between - and RH $18-=\theta_{s}$ (RH)/100, $\theta_{g}$ belng the saturetion water vapor pressure which is only a function of temperature. The expllcit water vapor term then becones $3.79 \times 10^{2} \mathrm{e}(\mathrm{RH}) / \mathrm{T}^{2}$.

Data on geographical and seasonal distributions of selractive Index have been examined, and It is found that the extremes are represented by Fairbanks, Alaska, In Apr1I and by San Junn, Puserto Rico, in July. The data for Washington, D.C. In October wore found to be approximately a mean between these two extrewes.

Ordinarily soundings go up only to 15 to 18 lax. However, at these levations the atmosphere 1s approximateiy 1sothermal (stratosphere), and the refractivo index distribution may bo easily extended to great helghts, at lpast to $30 \mathrm{~km}$, shlch $1 \mathrm{~s}$ as far as the 1sothermal coxdition prevailg(1I). (See Appendix 2, page 16).

There are 1imitations on the accuracy of both the refractive index formia, equation (50), and the meteorologleal observations in an individual soundiug. These livitation are discussed in $\Delta$ ppondix I, page 12, where there is shown to be an uncertalnty in the refractive Index calculations of the order of $7 \%$, about half bolng due to the uncertainty in the fornula coefficlents, and bals due to the errors of meteorological measurement, the humidity moagurenents being the least reliable.

\section{Computation of Refract1on.}

A method 18 sow presented for computing the refraction of radioPrequency ray through an atmosphere of lmown refractive index die-

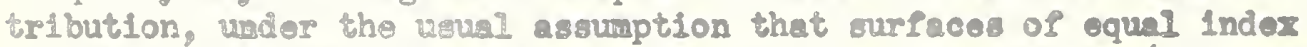
of refrection are spherical and concentric with the earth (horlsontel

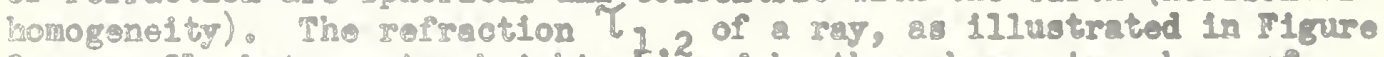
9, page 31, botween two holghts $h_{1}^{2}$ and $h_{2}$ through an atnosphere of lnown refracive index dictribution and waking an anglo $\theta$ with the

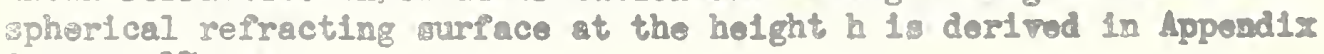
3, page 17, ass

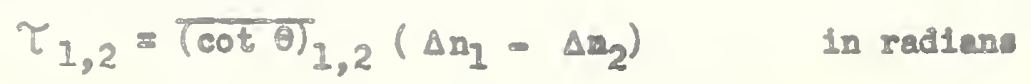

(11) "Tentative Tabies for the Properties of the Upper Ltmoaphere". C. N. Warfleld, N.A.C.A. Technicel Noto 1200 (1/47). 
whore, $\Delta n 18(n-1)$ and $\overline{(\cot \theta)}, 2$ is the mean value of the cotangent runction over the interval $h_{1}, h_{2}$, Oup problem is solved when wo aro ablo to obtain proper value of $(\cot \theta))_{1}$, the conpliceting fectors boing that $\theta$ is a runction of both $\Delta \mathrm{n}$ ahd $\mathrm{h}$ a determined from

Snoll' Iaw for concentric ophorical refreoting gurfaces, and further that. $\Delta \mathrm{n}$ is only known apirically as a function of $\mathrm{h}$, bolng fiton by a table of measured values as obtalned from redlosond data. Thus accoring to Snel1' Iaw, the angles 0 for a ray path through concentric sphpical refracting aurfeces are detorminod from the Porrula, $(12)$

$$
\text { nr } \cos \theta \approx n_{0} r_{0} \cos \theta_{0}=\text { constant }
$$

where: $5=a+h$, is the radius of the epherical refracting surface, at the levation $h$, and a is the earth's radius, and where the subscript zero refors to the ground level.

At mall elevation angles, $\theta_{0} \leqslant 10^{\circ}$, equation (7) transfors, neglecting quantities of second and higher order, to $(12)_{8}$

$$
\frac{\theta^{2}-\theta_{0}^{2}}{2}=\left(\Delta n+\frac{b}{2}\right)-\left(\Delta n_{0}+\frac{b_{0}}{2}\right)
$$

and we thon have, solving for $\theta$,

$$
\theta=\sqrt{\theta_{0}^{2}+2\left(\Delta n+\frac{h}{a}\right)-2\left(\Delta n_{0}+\frac{h_{0}}{c}\right)}
$$

whore $h_{0}$ is the etation elevation above nean sea level. This onbles us to calculate $\theta$ at any elevation, provided that the calculated value of 1 not appreciably greater than 100 , since we ere fiven for each ctation able of values of $\Delta \mathrm{n}$ agelnat $\mathrm{h}$. Tho $\Delta \mathrm{n}$ data come from the refractive inder distribution with holght, which aro obtained from the observed neteorologlcal data, as discussed in Section 3. It 1s necessary to take futo account oreral holght intervals, over each of which $(\cot \theta)$ nay bo conveniontly detor nined in the application of equation (6). It is show in Apperdis 4, page 19, how the nuber and s1se of these bolght 1ntervals 18 determined. Only four holght interval are required from the ground to $18 \mathrm{~km}$, namely, (1) surfeed to $0.5 \mathrm{~kg}$ (2) 0.5 to $2.5 \mathrm{~km}$ (3) 2.5 to $6.0 \mathrm{~km}$; (4) 6 to $18 \mathrm{~km}$. Above $18 \mathrm{~km}$ the contribution to the total refraction is mall and may bo shom to be given approximetely by $\tau=\Delta n_{78} \cot 9_{78}$ where the subseripts refer to the values of the quantities at $18 \mathrm{~km}$. Over these interval at these low angles, it was be show that $\overline{(\cot \theta)} \cong 1 / \theta_{m}$, wore $Q_{\text {m }}$ is the arithetical

(12) "Tropospheric Propagation and Radio-Moteorolog,", WPG 5, Reprint CRPL $\rightarrow 3$ (10/46). 
mean of $\theta$ on the interval. Thus, for the interval $\left(b_{7}, h_{2}\right)$, we have $\theta_{1}=\left(\theta_{1}+\theta_{2}\right) / 2$. When wo substitute this approrimation in equation (6), with $Q_{n}$ in radians, we obtain simply,

$$
\tau_{1,2}=\frac{\Delta n_{1}-\Delta n_{2}}{\theta_{m}} \quad \text { in redians } \quad\left(0 \leqq \theta_{0} \leqq 10^{\circ}\right)
$$

where the angles $\theta$ are determined from equation (9) above, and the $\Delta \mathrm{n}$ are obtained from meteorological data as described in Section 3.

Whenever the angle of arrival or departure $\theta_{0}$ is greater than $10^{\circ}$, the total refrection through the entire atmosphere is very small and can be obtained within an error of $4 \%$ from the simple formula derived from equation (6) in Appendix 4, page 19,

$$
\tau=\Delta n_{0} \cot \theta_{0} \quad \text { in radians } \quad\left(10^{\circ}<\theta_{0} \leqq 90^{\circ}\right)
$$

the approximation implied being that $\overline{\cot \theta} \cong \cot \theta_{0}$.

The mean ray bending for radio-frequency rays over the range of angles of arrival or departure has been obtained for San Juan, Puerto Rico (July) and Fairbanks, Alaska (April), as examples of extremes; and for Washington, D.C. (October) as a mean case. These data have been plotted in' Figures 10 and $10 a$, pages 32-33. In these same figures, we have plotted our computed values of optical refraction for Washington, D.C., in October and compared them with the moan observed astronomical refraction data (13) as adjusted to these same Eurface refraction conditions. Optical refraction for Washington, D.C. in October was computed by the methods of this section, using the optical refractive index distribution obtained by neglecting the explicit water vapor term in the radio-prequency refractive index computation. Good agreement is obtained wilch provides check of the computational procedure.

It is now possible to determine the ray path as function of the distance d along the earth's surface as illustrated in Figure 9, page 31. $\theta$ has been determined from equations 7 or 9 , and $\tau_{1,2}$ has been deternined from equations 10 or 11 and 1 t may be shown from geometric considerations in Figure 9 that:

$$
\tau_{1,2}=\frac{d_{1,2}}{a}+\left(\theta_{1}-\theta_{2}\right) \quad \text { in radians }
$$

and we then have: $d_{1,2}=a\left(\tau_{1,2}+\theta_{2}-\theta_{1}\right)$

where: $\tau_{1}, 2, \theta_{2}$ and $\theta_{1}$ are expressed in radians, and $d$ is expressed in the same' unit as a, the oarth's redius.

(13) "Astronong," Vol. I-Solar System by H. N. Russell, R. S. Dugan and J. Q. Stewart, Ginn, 1945. 


\section{Conclueion}

It has been found that the actual ir rofraction in the lower atmomphere deviates conslderably ron that which bes been assured when we use an effective radius of the earth equal to $4 / 3$ of 1 ts actual valuo an allowance for this rerractlon. Thus, al though the $4 / 3$ arth' redius asumption provides roasonably good apm

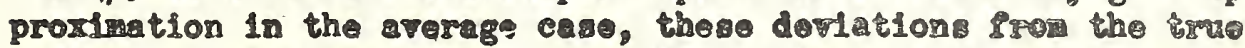
refraction have boon shown to be fairly large both ar a Puction of altitud and of geographical location. The practical tirportence of these deviations in terms of rleld-intenelty calculations has not as yot-been ovaluated, but they way ture out to require another type of refraction approximation which allows for the observed variations wth respect to helght and geogrephical location. 


\section{Appendix 1. Estimate of Uncertainty in Application of Refractive Index Formula for Moist Air.}

There are Iimitations on the accuracy of both the refractive index formula and the meteorological observations in an individual sounding.

\section{A. Uncertainty in the Refractive Index Formula.}

The formula for the refractive index of molst air, equation (5), page 7, is based on a series of separate laboratory determinations of the dielectric constants of dry air and water vapor(14). The contributions of each are then combined to yield equation (5),

$$
(n-1) \times 10^{6}=\frac{79 p}{T}(1+4800 \mathrm{e} / \mathrm{pT})
$$

(a) Drr Air Refractive Index

The refractive index, $n_{d}$, of dry air is given by:

$$
\left(n_{d}-1\right) \times 10^{6}=79 p_{d} / T
$$

where $\mathrm{p}_{\mathrm{d}}$ is the partial pressure of dry air. There have been many moasurements taken on the dielectric constant of dry air. The most recent determination has been made by Hector and Woorniey (14). From their data the coefficient in equation (16) is computed to be 76.5 , whereas the arerage value obtained by all workers in the fleld is 77.9. It is pointed out in the same paper that the internal consigtency of each worker's data has been better than the agreement from observer to observer. The entire range o: the sixteen determinations, the first of which was made by Boltzmann in 1874, is from 72.8 to 80.8. The computed probable error is $4 \%$ of the mean. It should be pointed out that the coefficient in equation (16) is about $1 \%$ larger than the mean value for all workers in the fleld. Hence, we take $5 \%$ as a reasonable value of the uncertainty in the dry air contribution.

(b) Water Vapor Refractive Index.

The refractive index, $n_{w}$, of water vapor is given by:

$$
\left(n_{w}-1\right) \times 10^{6}=\frac{79 \theta}{T}(1+4800 / T)
$$

According to reference 9, the best determinations over a range of temperature values are those due to Sknger and those due to Stranathan:

$$
\left(q_{W}-1\right) \times 10^{6}= \begin{cases}\frac{8}{\mathrm{~T}}\left(68+\frac{3.78 \times 10^{5}}{\mathrm{~T}}\right) & \text { sunger } \\ \frac{8}{\mathrm{~T}}\left(73+\frac{3.73 \times 10^{5}}{\mathrm{~T}}\right) & \text { Stranathan }\end{cases}
$$

(14) "Dielectric Constants of Eight Gases," by L. G. Hector and D. L. woernley, Phys. Rev., Vol. 69, Nos. 3, 4, p.101 (2/46) 
The value of the water vapor refractive index actually used in obtaining equation (5) is given by equation (17):

$$
\left(n_{w}-1\right) \times 10^{6}=\frac{790}{T}\left(1+\frac{4800}{T}\right)
$$

Instead of the mean. value of equations (18) and (19), which iss

$$
\left(n_{w}-1\right) \times 10^{6}=\frac{790}{T}\left(0.89+\frac{4750}{T}\right)
$$

Even assuming a temperature of $50^{\circ} \mathrm{C}$, the values of $(\mathrm{n},-1) \times 10^{6}$ obtained from equation (17) do not differ from those calculated from equations (18) and (19) by more than $2.5 \%$.

Wo consider now the uncertainty in the formula of equation (5) for $(n-1)=10^{6}$ for moist air due to the respective errors in $\left(n_{d}-1\right) \times 10^{6}$ for dry atr and $\left(n_{y}-1\right) \times 10^{6}$ for water rapor. The surface values of these quantities for typical station, like Washington, D.C., in October is $(n-1) \times 106=332$ units, which is composed of $\left(n_{d}-1\right) \times 10^{6}=281$ units and $\left(n_{w}-1\right) \times 10^{6}=51$ units. Thus $5 \%$ orror in the dry air contribution, and a $2.5 \%$ orror in the water vapor contribution, lead to a weighted error in the formula for the refractive index of moist air of $4 \%$.

\section{B. Upcertaintr in Meteorological Data.}

\section{(a) Der Air Refractive Index}

The following orror data used in discussing the dry air refractive Index has been computed from data in V.S. Weather Buresu memoranda dated Mey 15, 1943 and May 19, 1943, and is based on Gregg' a Standard Atmosphere wich represents arerage U.S. date at $40^{\circ} \mathrm{N}$ latitude.

Table 18 Probable Frror in Computed Pressure and Temperature at Fixed

\begin{tabular}{|c|c|c|c|c|c|}
\hline $\begin{array}{l}\text { Fixed } \\
\text { Altitude }\end{array}$ & $\begin{array}{c}\text { Pressure } \\
\text { mb }\end{array}$ & $\begin{array}{l}8 \text { Brror in } \\
\text { Computed } \\
\text { Pressure }\end{array}$ & $\begin{array}{c}\text { Temp. } \\
\text { OC }\end{array}$ & $\begin{array}{l}\text { \% Error in } \\
\text { Computed } \\
\text { Temperature. }\end{array}$ & $\begin{array}{l}\text { \% Error in } \\
\left(n_{d}-1\right) \times 10^{6}\end{array}$ \\
\hline $\begin{array}{r}10,000 \mathrm{ft} \\
20,000 \mathrm{ft} \\
10 \mathrm{~km} \\
13 \mathrm{~km} \\
16 \mathrm{~km}\end{array}$ & $\begin{array}{l}701.1 \\
471.8 \\
270.5 \\
171.0 \\
107.0\end{array}$ & $\begin{array}{l} \pm 0.1 \\
\pm 0.28 \\
\pm 0.59 \\
\pm 0.82 \\
\pm 0.93\end{array}$ & $\begin{array}{l}-1.4 \\
-20.6 \\
-44.5 \\
-55 \\
-55\end{array}$ & $\begin{array}{l} \pm 0.3 \\
\pm 0.48 \\
\pm 0.66 \\
\pm 0.69 \\
\pm 0.69\end{array}$ & $\begin{array}{l} \pm 0.4 \\
\pm 0.8 \\
\pm 1.3 \\
\pm 1.5 \\
\pm 1.6\end{array}$ \\
\hline
\end{tabular}
Levels for a Single Sounding for U.S. Weather Stations. 
The error below altitudes of $20,000 \mathrm{ft}(\sim 6 \mathrm{~km})$ in $(\mathrm{n}-1) \times 10^{6}$ for moist air, due to the error in the dry air refractive index, must be less than about 0.8 , At $10 \mathrm{~km}$ and higher, the error is larger, but there is a negligible water vapor contribution at these altitudes and so the tabulated error then represents the totel error. Below about $10 \mathrm{~km}$, we must also consider the effect of the water vapor refractive index contribution, $\left(n_{w}-1\right) \times 10^{6}$.

\section{(b) Water Vapor Refractive Index}

For our purposes the relative humidity error is taken as $\pm 10 \% \mathrm{RH}$ ( $\pm 10 \mathrm{RH}$ units) at all values of relative humidity. At elevations from $10 \mathrm{~km}$ on up, the water vapor contribution is negligible because of the negligible amount of water vapor at these elevations. The water vapor contribution, equation (17), may now be written:

$$
\left(n_{w^{-1}}\right) \times 10^{6}=\frac{79 e_{s}(\mathrm{RH})}{\mathrm{T}}\left(1+\frac{4800}{\mathrm{~T}}\right) \cong \frac{79 \theta_{\mathrm{s}}(\mathrm{RH})(4800)}{\mathrm{T}^{2}}
$$

where the last approximation holds at ordinary temperatures. Now, we see in Table 1 that the error in the temperature measurement is of the ordar of 1 , below $10 \mathrm{~km}$. An examination of equation (17) w111 show that the error in $\left(n_{w-1}\right) \times 10^{6}$ for water vapor, due to the temperature error, is of the order of $2 \%$. The corresponding error in $e_{5}$, the saturation specific humidity, due to the 1 i error in $\mathrm{T}$, is less than 1\%. The error due to the uncertainty in the relative humidity measurement has been calculated for a typical station, taken as. Washington, D.C., in October, and tabulated in Tablo ?, pago 15. The total percentage orror in $\left(n_{w}-1\right) \times 10^{6}$ for water vapor, listed in columan 3, was obtained by adding a $1 \%$ error due to $e_{3}$, a $2 \%$ error due to the effect of the temperature, and the equivalent percentage error due to an absolute error of $\pm 10 \mathrm{RH}$ units for any value of relative humidity. At the surface, the error data are oilted sinoe humidity measurements are made with a sling psychrometer and the accuracy of the data far exceeds that obtainable with the radiosonde humidity element.

We thus see that there is a weighted percentage error of about 3 below $20,000 \mathrm{ft}(\simeq 6 \mathrm{~km})$ in the refractive index computation of moist air due to errors in measurement of the meteorological elements. The $3 \%$ includes $2 \%$ for the water vapor contribution, and $1 \%$ for the dry air contribution.

Our conclusion then is that the total uncertainty in the refractive index calculations is of the order of $7 \%$, about $4 \%$ being due to the uncertainty in the coefficients of the formula, and about $3 \%$ due to the errors of measurement of the meteorological factors. 


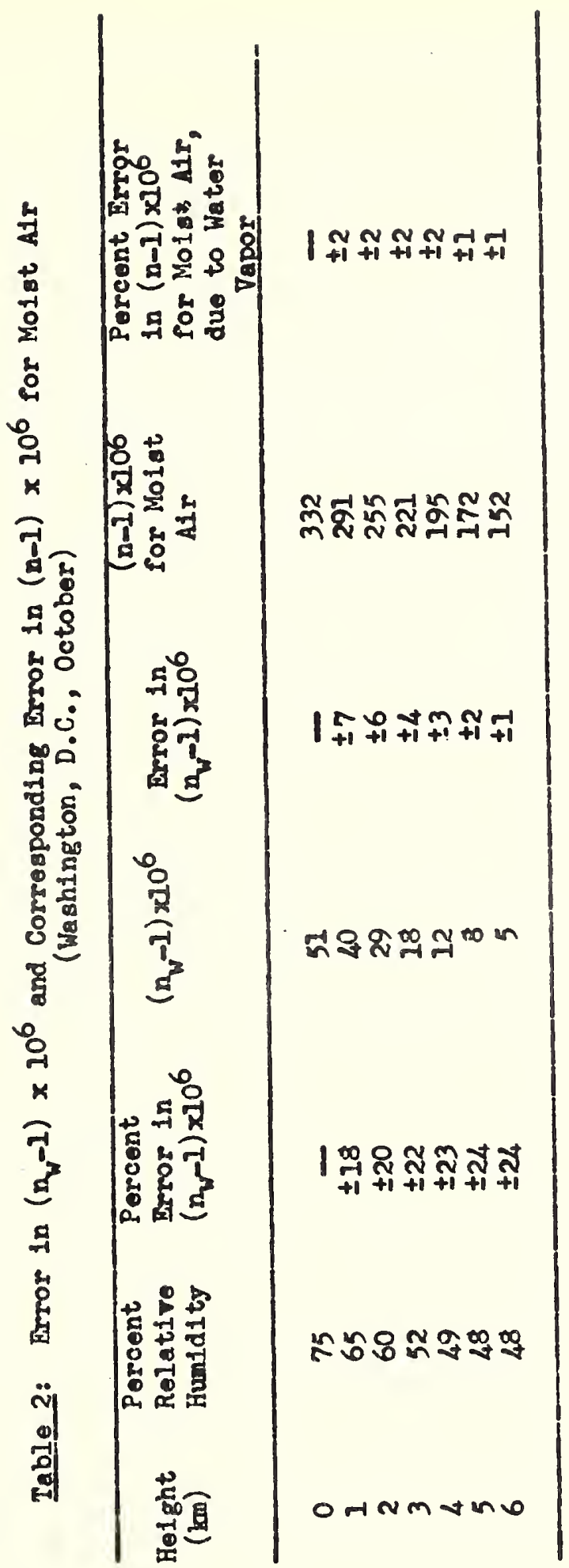


Appondix 2. Extrapolation of Refractive Index Data to $30 \mathrm{~km}$

The expression for the pressure in an 1sothermal atmosphere is given by:

$$
p=p_{0} e^{-\left(h-h_{0}\right) / R^{\prime} T_{0}}
$$

wheres $T_{8}$ is the constant temperature of the stratosphere in ${ }^{\circ} \mathrm{K}$, but which way vary with season.

Po is the surface pressure in mb which in this case refers to the base of the stratosphere, but the actual value is unimportant for the present application as shown below.

$R^{\prime}$ is the ges constant for the dry stratosphere.

$b \rightarrow h_{0}$ is the helght referred to the base of the stratosphere.

Assuning no water vapor at these elevations, the refractive index is given by:

$$
(n-1) \times 10^{6}=79 p / T_{0}=\frac{79 p_{0}}{T_{B}}-\left(b-h_{0}\right) / R^{\prime} T_{*}
$$

and hence, $\log (n-1)=k_{1}-k_{2} h$

where $k_{1}$ and $k_{2}$ are constants. Thus by plotting the stratosphere data that we have for the location concernod ( 800 Figure 11, page 34), we should get a straight line which allows us to extrapolate refractive index date to great helghts. In fact, we find that $(n-1)$ reduces to $4 \times 10^{-6}$ units at an elevation of $30 \mathrm{~km}$ at Washington, D.C. In Octobpr, If we assume the stratosphere to be isothermal to that elevation. 


\section{Appendix 3 . Derivation of Formula for Refraction. $\tau$. of a Radio Rar.}

Snell's law for spherical, refracting surfaces is: nr $\cos \theta$ a constant The expression for curvature at a polnt on the ray path, to bo derived below from equation $(7)$, is:

$$
\frac{d \tau}{d \theta}=\frac{1}{\rho}=-\frac{1}{n} \frac{d n}{d h} \cos \theta
$$

where: $P$ is the radius of ray curvature at a point on the ray.

$\left(\frac{d n}{d h}\right)$ is the vertical gradient of refractive index at the point in question.

$\left(\frac{d \tau}{d s}\right)$ is the rate of change of curvature at any point along the path.

Differentiating equation (7) (shown abore), with respect to height, $h$, nemeabering that $r=a+b$, wo haves

$$
\begin{aligned}
& \frac{1}{n} \frac{d n}{d h}+\frac{1}{r}-\tan \theta \frac{d \theta}{d h}=0 \\
& \text { and } \frac{1}{r} \cos \theta-\sin \theta \frac{d \theta}{d h}=-\frac{1}{n} \frac{d n}{d h} \cos \theta
\end{aligned}
$$

From the infinitesimal section of the ray path in Figure 12, page 35, we haves

$$
\begin{aligned}
d s^{2} & =d h^{2}+r^{2} d \phi^{2} \\
\text { and } r \frac{d \phi}{d s} & =\cos \theta \\
\text { and } \quad \frac{d h}{d s} & =\sin \theta
\end{aligned}
$$

and, substituting in equation (21), for $\cos \theta$ and sin $\theta$, wo haves

$$
\frac{d(\phi-\theta)}{d s}=-\frac{1}{n} \frac{d n}{d h} \cos \theta
$$

From geometrical considerations for the quadrilateral indicated by dashed Iines in Figure 12,

$$
\left(\frac{\pi}{2}+\theta\right)+(\pi-\Delta \tau)+\Delta \phi+\left[\frac{\pi}{2}-(\theta+\Delta \theta)\right]=2 \pi
$$

and hence, $\Delta \tau=\Delta \phi-\Delta \theta \quad$ and, $\frac{\Delta \tau}{\Delta \theta}=\frac{\Delta(\phi-\theta)}{\Delta s}$ 
Passing to the linit as $\Delta \theta \rightarrow 0$, we have, substituting in equation (22),

$$
\frac{d \tau}{d s}=-\frac{1}{n} \frac{d n}{d h} \cos \theta
$$

Integreting between the altitudes $h_{1}$ and $h_{2}$,

$$
\tau_{1,2}=-\int_{n_{1}}^{n_{2}} \frac{1}{n} \frac{d n}{d n} \cos \theta d s=-\int_{n_{1}}^{n_{2}} \frac{1}{n} \cot \theta d n
$$

and since $n \simeq 1, \quad \tau_{1,2}=-\int_{n_{1}}^{n_{2}} \cot \theta d x$

Now, $\frac{d n}{d b}=\frac{d(\Delta n)}{d h}$ and changing the variable of Integration to $\Delta n$, by means of the relation $n=1+\Delta \mathbf{n}$

wo have $\tau_{1,2}=-\int_{\Delta n_{1}}^{\Delta n_{2}} \cot \theta d(\Delta \mathrm{n})$

By the definition of the mean value of $\cot \theta$ over the interval $\left(\Delta n_{1}, \Delta n_{2}\right)$,

$$
\overline{(\cot \theta)_{1,2}}=\frac{\int_{\Delta n_{1}}^{\Delta n_{2}} \cot \theta d(\Delta n)}{\left(\Delta n_{2}-\Delta n_{1}\right)}
$$

and, therefore, we pave Plmally,

$$
\tau_{1,2}=\overline{(\cot \theta)_{1,2}}\left(\Delta n_{1}-\Delta n_{2}\right)
$$




\section{Appendix 4. Applications of Formula for Repraction of a Radio pay.}

To determine the smallest number and, therefore, the largest size of the height intervals needed, at angles $\phi_{0} \Xi 10^{\circ}$, consiatent with the $7 \%$ orror arising from the computation of $\Delta \mathrm{n}$ as shown in Appendix 1 , page 12, we consider the following facts:

Under the condition that $\frac{d n}{d h}=\frac{\Delta n-\Delta n_{1}}{h-h_{1}}$ is constant in the interval $\left(h_{2}, h_{1}\right)$ we have,

$$
\frac{h_{1} \text { we have, }}{(\cot \theta)_{1,2}}=\frac{\int_{\Delta n_{1}}^{\Delta n_{2}} \cot \theta d(\Delta n)}{\Delta n_{2}-\Delta n_{1}}=\frac{\int_{h_{1}}^{b_{2}} \cot \theta d h}{h_{2}-h_{1}}
$$

Now, under the same condition, Snell's law for low angles of arrival in the interval becomes,

$$
\begin{aligned}
\frac{\theta^{2}-\theta_{1}^{2}}{2}=\left(\Delta n+\frac{b}{a}\right)-\left(\Delta n_{1}+\frac{h_{1}}{a}\right)=\left(\frac{\Delta n-\Delta n_{1}}{h-h_{1}}+\frac{l}{a}\right)\left(h-h_{1}\right) \\
=\frac{b-b_{1}}{k a}
\end{aligned}
$$

where $\frac{1}{k a}=\frac{1}{a}-\frac{1}{p}, p$ being the radius of curvature of the ray.

This shows $\theta^{2}$ to be a linear function of $h$ over the interval. We therefore plot $\theta^{2}$ against $h$, to examine how wide are the intervals over wich this linearity is indicated. An example of this relationship is show in Figure 13, page 36, for the case $\theta_{0}=0$ for Washington, D.C., in October. This empirical relation makes it possible to introduce a great simplification in determining the value of $(\cot B)$ over such an interval. For, at these low angles cot $\theta \cong 1 / \theta$, and it may be show thet $\overline{\cot \theta}=1 / \theta_{\mathrm{m}}$, where $\theta_{\mathrm{m}}$ is the arithmetical mean of $\theta$ on the interval, $\theta_{. g}$, over the interval $\left(h_{1}, h_{2}\right), \theta_{\text {m }}=\left(\theta_{1}+\theta_{2}\right) / 2$. From Snell's law nrcos $\theta=$ constant, we heve:

Thus,

$$
\begin{aligned}
& \cot \theta=k \theta \frac{d \theta}{d h} \\
& \overline{\cot } \theta=\frac{\sqrt{h_{1}} h_{2} \cot \theta d h}{h_{2}-h_{1}}=k a \frac{\theta_{2}-\theta_{1}}{h_{2}-h_{1}}
\end{aligned}
$$

and therefore, for small angles, $\overline{\cot \theta}=\frac{2}{\theta_{1}+\theta_{2}} \equiv \frac{1}{\theta_{m}}$.

When this ralue of $\cot \theta$ is substituted in equation 6 , we obtain, simply,

$$
\tau_{1,2}=\frac{\Delta n_{1}-\Delta n_{2}}{\theta_{m}} \quad \text { in radians } 0 \leqq \theta_{0} \leqq 10^{\circ}
$$

In the example shown in Figure 13, we see that $\theta^{2}$ can be considered arbitrarily to be a linear function of $h$ over four separat intervals from 
the ground to $18 \mathrm{~km}$, namely, (1) suriace to $0.5 \mathrm{~km}$; (2) 0.5 to $2.5 \mathrm{~km}$; (3) 2.5 to $6.0 \mathrm{~km}$; and (4) 6 to $18 \mathrm{~km}$. Above $18 \mathrm{~km}$, the contribution to the total refraction is small and may be shown to be given approximately by $\tau=\Delta n_{18} \cot \theta_{18}$, where the subseripts refer to the values of the quantities at $18 \mathrm{~km}$. In general, the same intervals may be used at all locations, since the shape of the $\theta^{2} \nabla 8 \mathrm{~h}$ curve does not change appreciably from location to location.

We show at this point aimple formula for the refraction of a radio ray tangential to the earth's surface in an atmospheric layer in which an effoctive earth's radius factor $\underline{k}$ may bo used. Equation (24) shows that in this case,

$$
\frac{\theta^{2}}{2}=\frac{h}{k a}
$$

In addition the well-known distance-helght formula for a ray tangent to the earth's surface in an atmosphere with effective earth's radius Pactor $k$ is:

$$
d=\sqrt{2 k a h}
$$

Substituting these relations in equation (12), page 10, we have,

$$
\begin{aligned}
\tau_{1,2} & =\frac{d_{1,2}}{a}+\left(\theta_{1}-\theta_{2}\right) \\
\tau & =\sqrt{\frac{2 h}{a}}\left(\sqrt{k}-\frac{1}{\sqrt{k}}\right), \quad \theta_{1} \text { being } 0 .
\end{aligned}
$$

and

At large angles, $\theta, 10^{\circ}$, we now derive the following expression for the total refractioh,

$$
\tau=\Delta n_{0} \cot \theta_{0} \quad \text { in radians }
$$

the approximation bolng limpliod that $\overline{(\cot \theta)} \cong \cot \theta_{0}$, in equation (6)

$$
\left.\tau_{1,2}=\overline{\cot \theta}\right)_{1,2}\left(\Delta n_{1}-\Delta n_{2}\right)
$$

We use the subscript o for the ground vilue, the subscript 18 at $\mathrm{h}=18 \mathrm{kan}$, and the subscript fo for $h=a$ Equation (6) hay then be transformed to:

$$
\begin{aligned}
\tau_{0, \infty} & =\tau=\overline{\cot \theta)_{0,18}}\left(\Delta n_{0}-\Delta n_{18}\right)+\overline{(\cot \theta)} \\
\text { or } \tau & =\overline{(\cot \theta)_{0,18}}\left(\Delta n_{0}-\Delta n_{18}-0\right)
\end{aligned}
$$


For average refractive index distributions, i.e., there are no height intervals where the downward ray curvature exceeds earth curvature and neglecting ionospheric effects, then as $h$ increases, $\Delta n$ approaches zero and $\theta$ becomes uniformly larger because of the geometry of the ray path. This means that cot $\theta$ decfeases uniformly with height, and hence, the average value $(\cot \theta)_{18, \infty}$ is less than $(\overline{\cot \theta})_{0,18^{\circ}}$ Now, $\Delta n_{18}$ is less than $\Delta n_{0} / 10$ at all geographical locations and for all seasons.

$$
\text { Also, for angles } \theta_{0}=10^{\circ} \text { or higher, } \frac{(\cot \theta)_{18,00}}{(\cot \theta)_{0,18}} \leqslant \frac{1}{2}
$$

Therefore, at most the second term in equation (23a) is 5 of the first torm.

In addition, from consideration of data at San Juan, Puerto Rico, in July, using the large-angle formula (eq.(1I)) for $\theta=10^{\circ}$ which is the case of largest refraction considered in this report, the largest error we make by taking $(\overline{\cot \theta})_{0,18} \approx \cot \theta_{0}$ is $4 \%$. This, at $\theta_{0}=10^{\circ}$, the error made using the high-angle formula is of the order of 9,6 , with the error decreasing rapidly as $\theta_{0}$ increases from $10^{\circ}$.

Table 3 shows a sample computation using the ray tracing method of this report. 


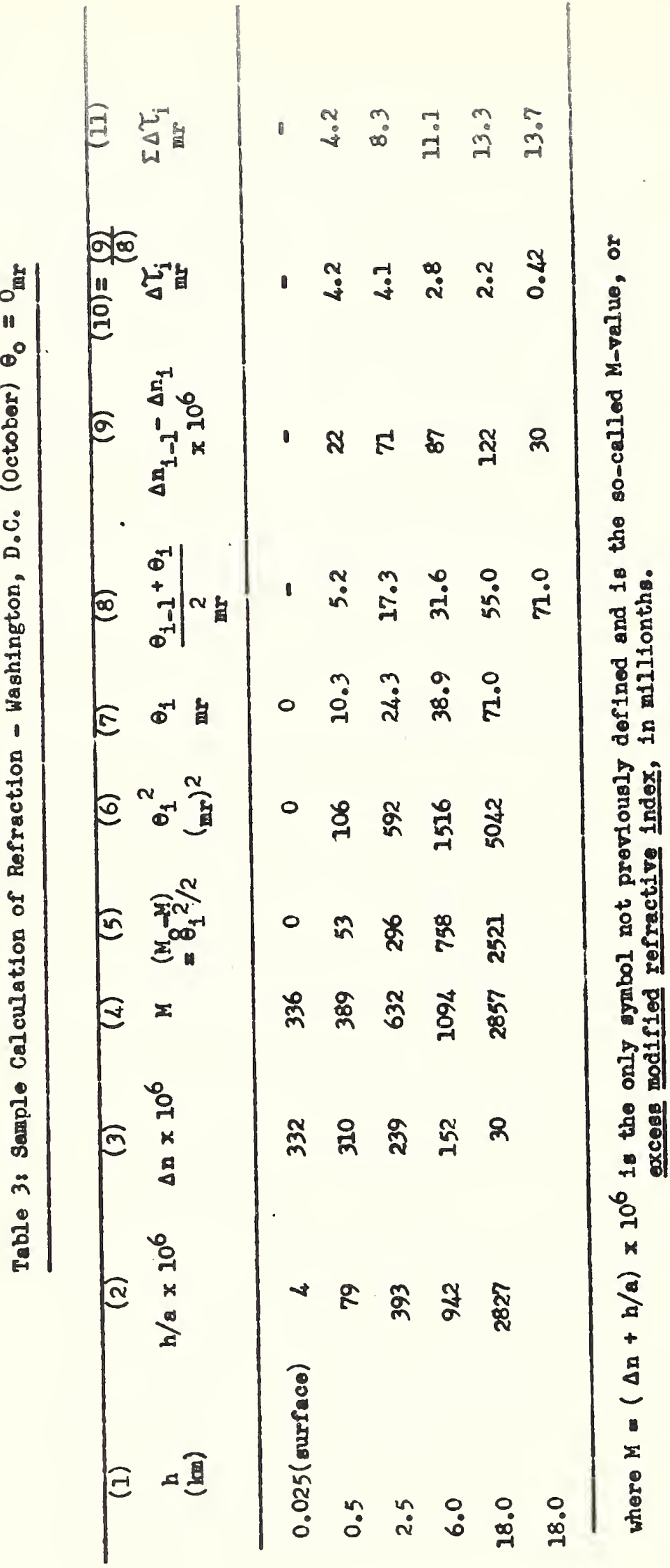


$1 \exists \exists \unlhd$ JO SON $\forall S \cap O H \perp$ ' 4 ' 1 H.9I3H

$\stackrel{2}{\stackrel{2}{*}}$

in

웅

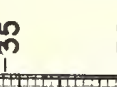

욤

$\stackrel{2}{2}$

$\stackrel{2}{\circ}$

$\underline{1}$

으

$\frac{1}{1} \quad 0$

\\.

ב-

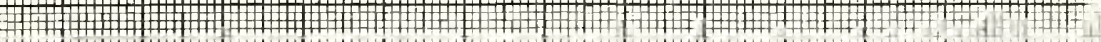

오

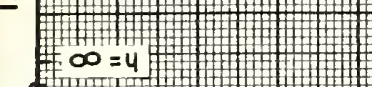

:

(9)

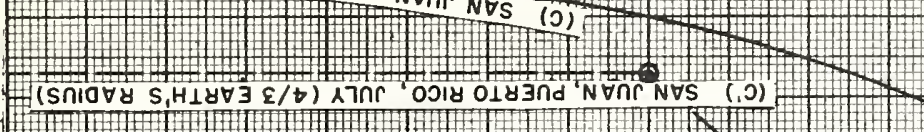

$\circ$

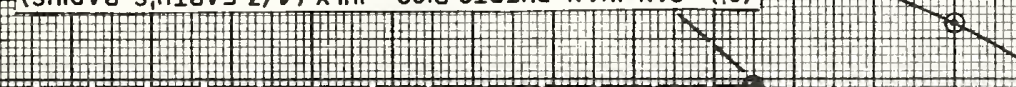

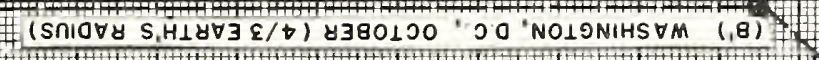

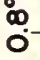

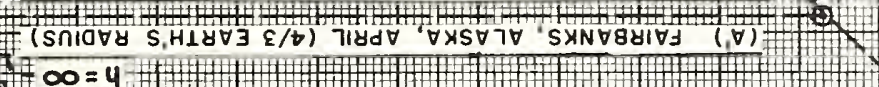

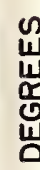

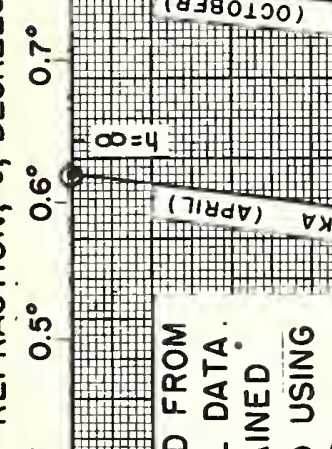

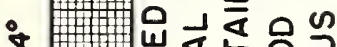

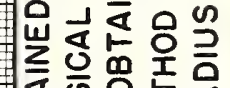

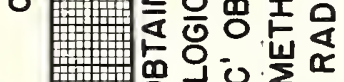

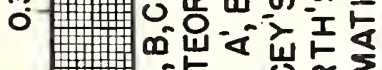

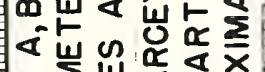

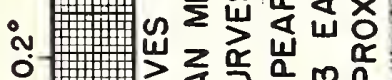

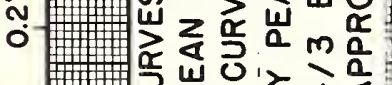

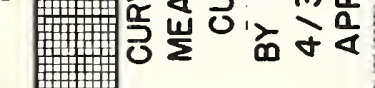

$\stackrel{\circ}{\circ}$

○

$\underline{\infty}$

$\underline{ \pm}$

(1)

曲( )

$+\div$

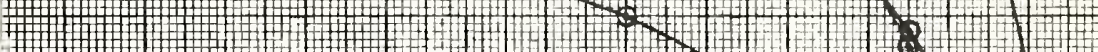

屎

(弗

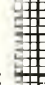

$\left(\begin{array}{l|l|}\hline \\ \hline\end{array}\right.$<smiles>[Li]</smiles><smiles>[C+]1C=C1</smiles>

$(1, \ldots$

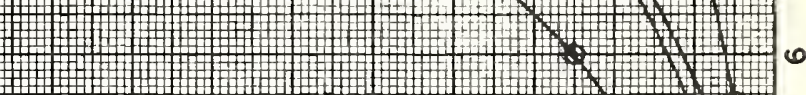

$\pm$

$\pm$

으 응

$\underline{\infty}$

৫

능 兵

ली

$r \infty$

II

은

뚱

以

\& I

이

3

은

告

z

แ.

w

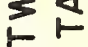

崩文

(c)

응

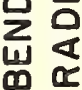

í 


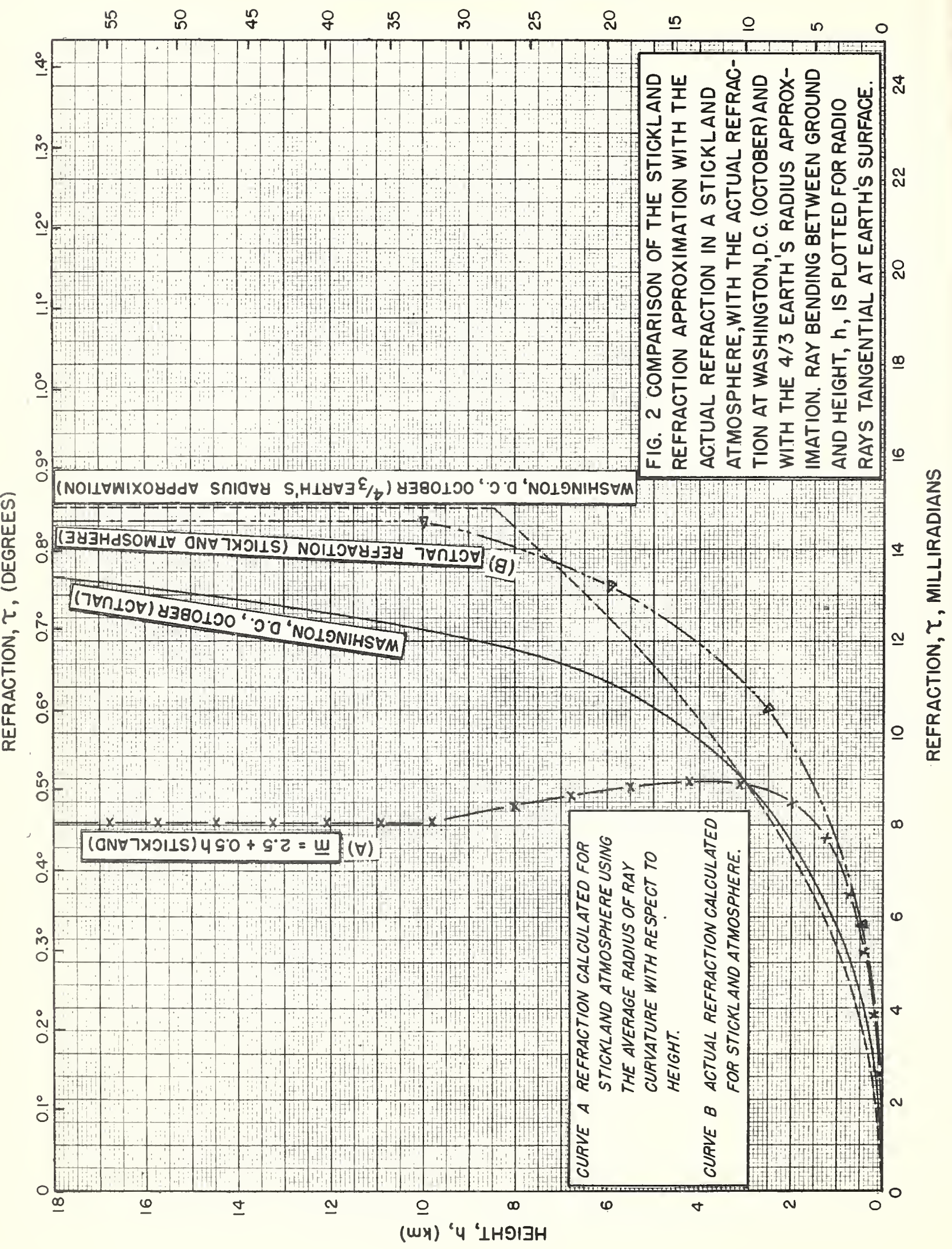


FIg. 3 PRESSURE-TEMPERATURE TERM FOR THE REFRACTIVE INDEX COMPUTATION (NUMBERS ON SLANT LINES ARE VALUES OF $79 \frac{D}{7}$ )

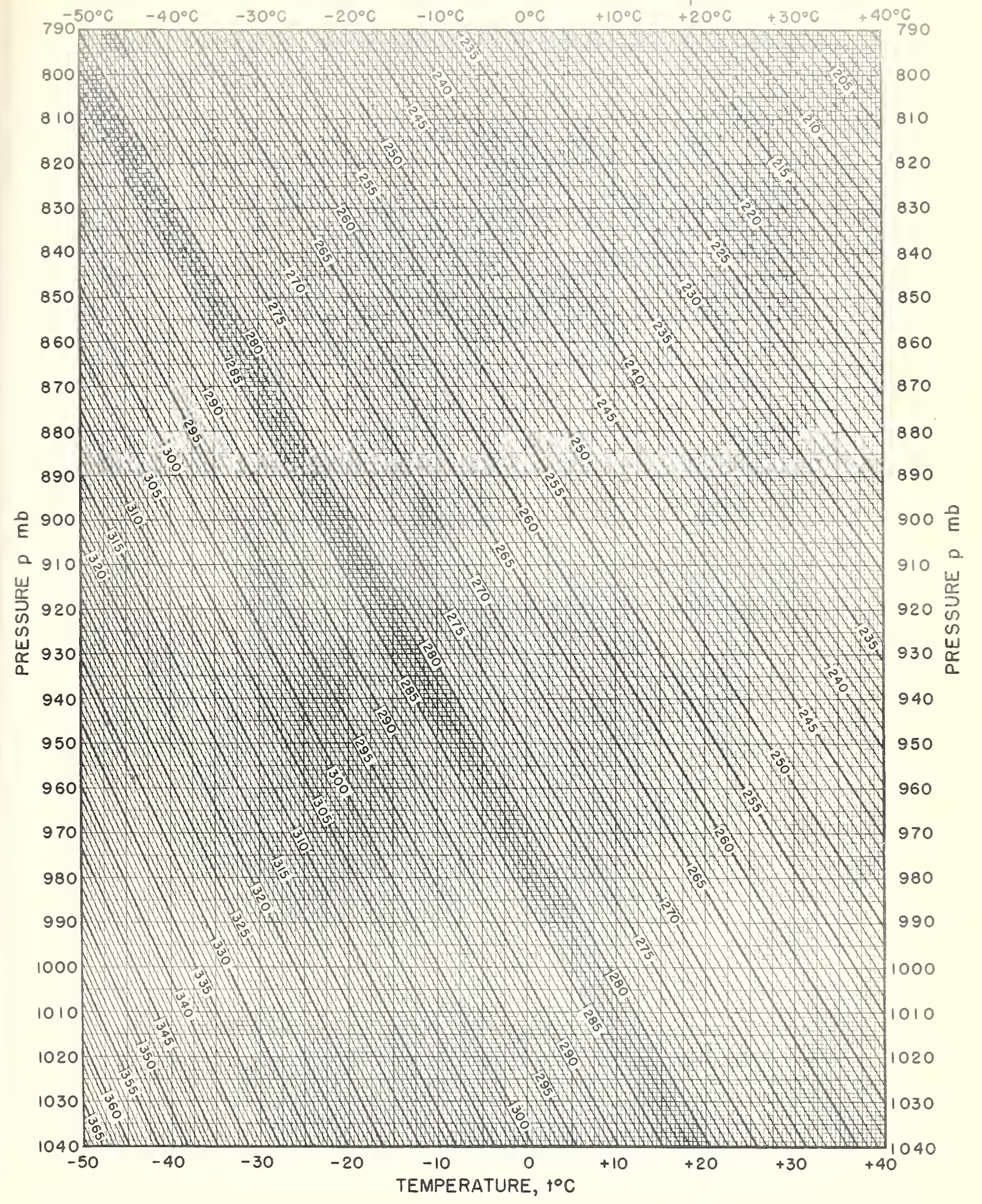


FIg. 4 PRESSURE - TEMPERATURE TERM FOR 'THE REFRACTIVE INDEX COMPUTATION (NUMBERS ON SLANT LINES ARE VALUES OF $79 \frac{\mathrm{D}}{\mathrm{T}}$ )

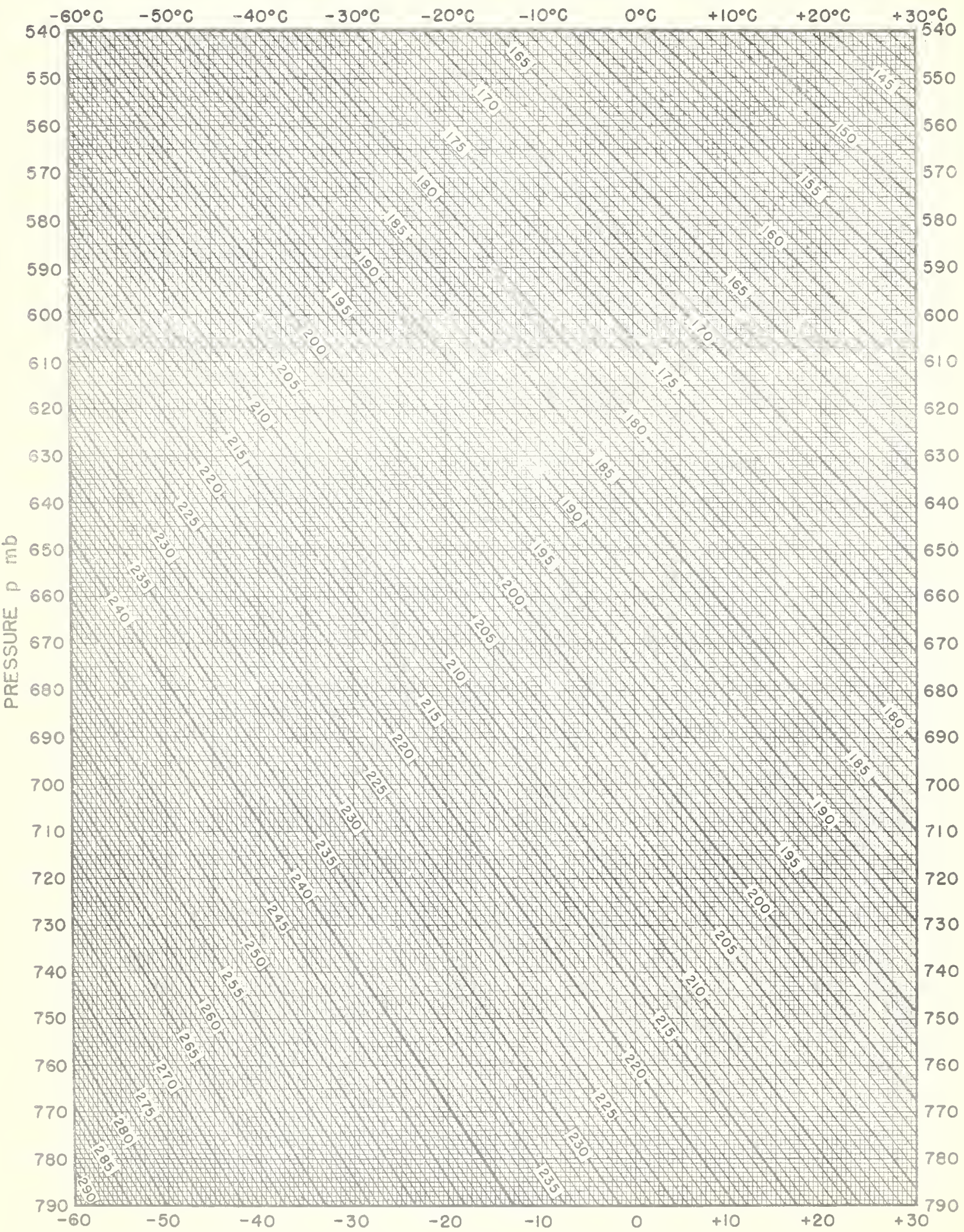

TEMPERATURE, $\uparrow^{\circ} \mathrm{C}$ 





Fig. 6 PRESSURE - TEMPERATURE TERM FOR THE REFRACTIVE INDEX COMPUTATION (NUMBERS ON SLANT LINES ARE VALUES OF $79 \frac{P}{T}$ )

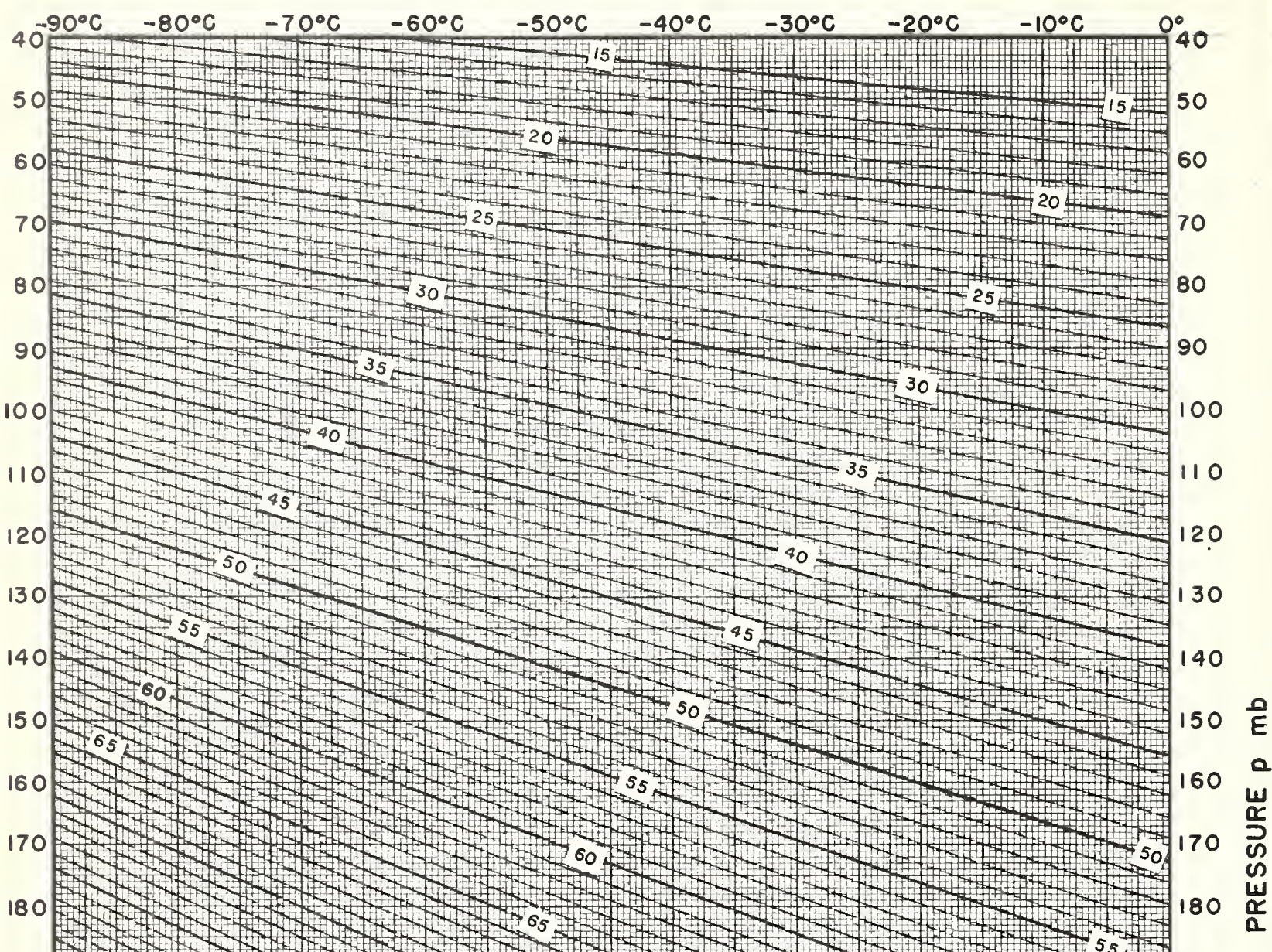

200

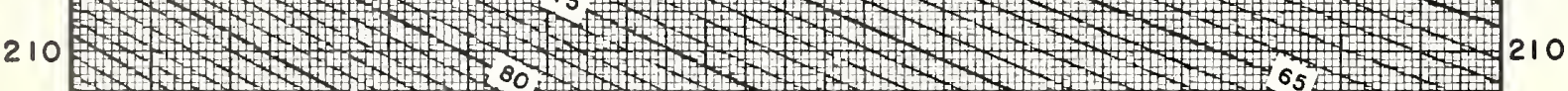

220

$230 \times 2 \times 20$

250

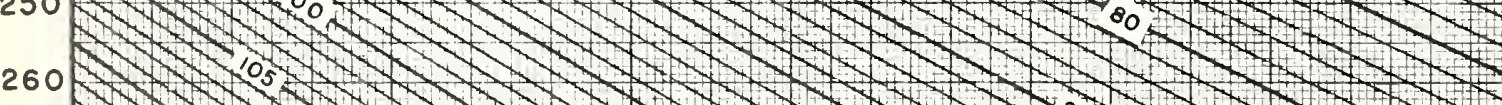

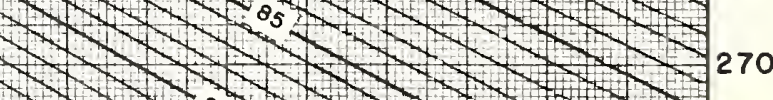

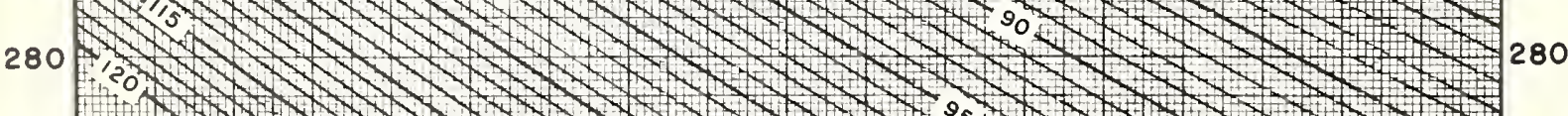

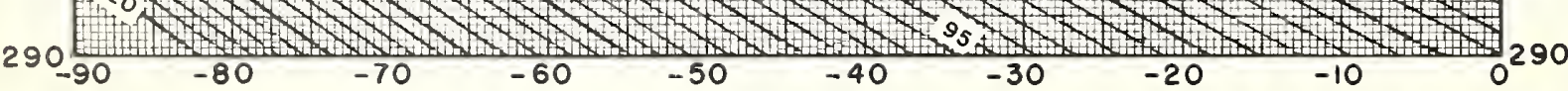




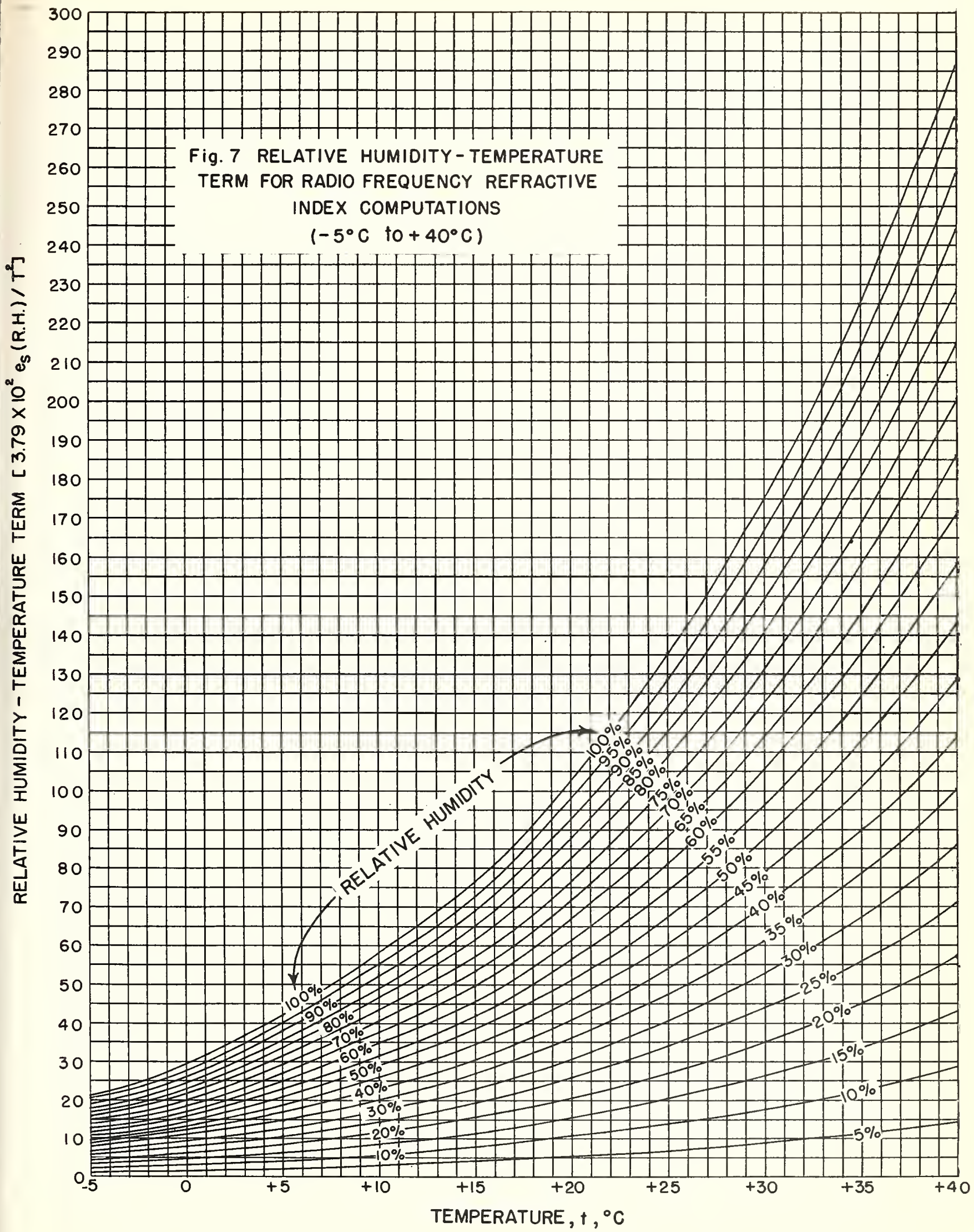




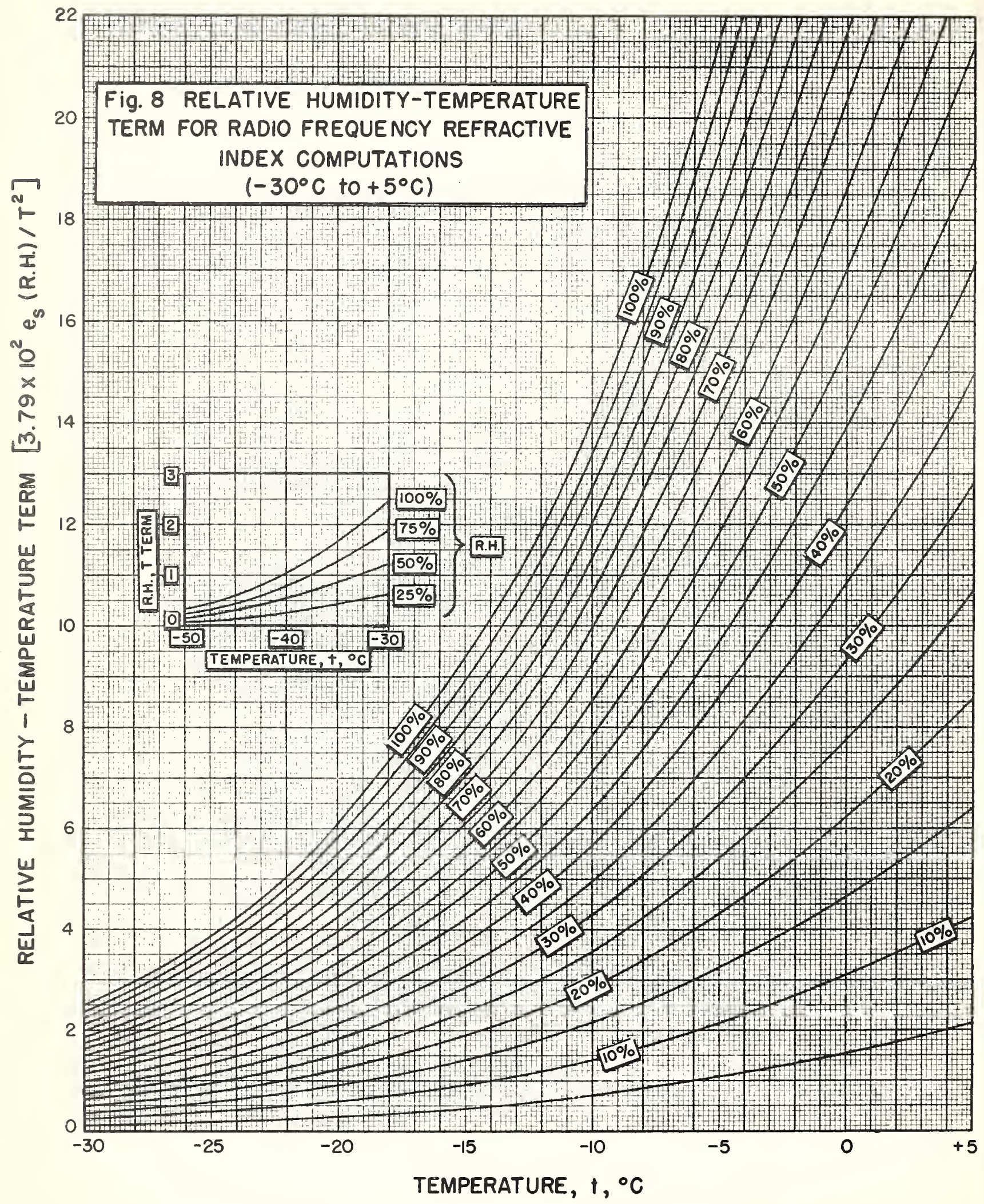




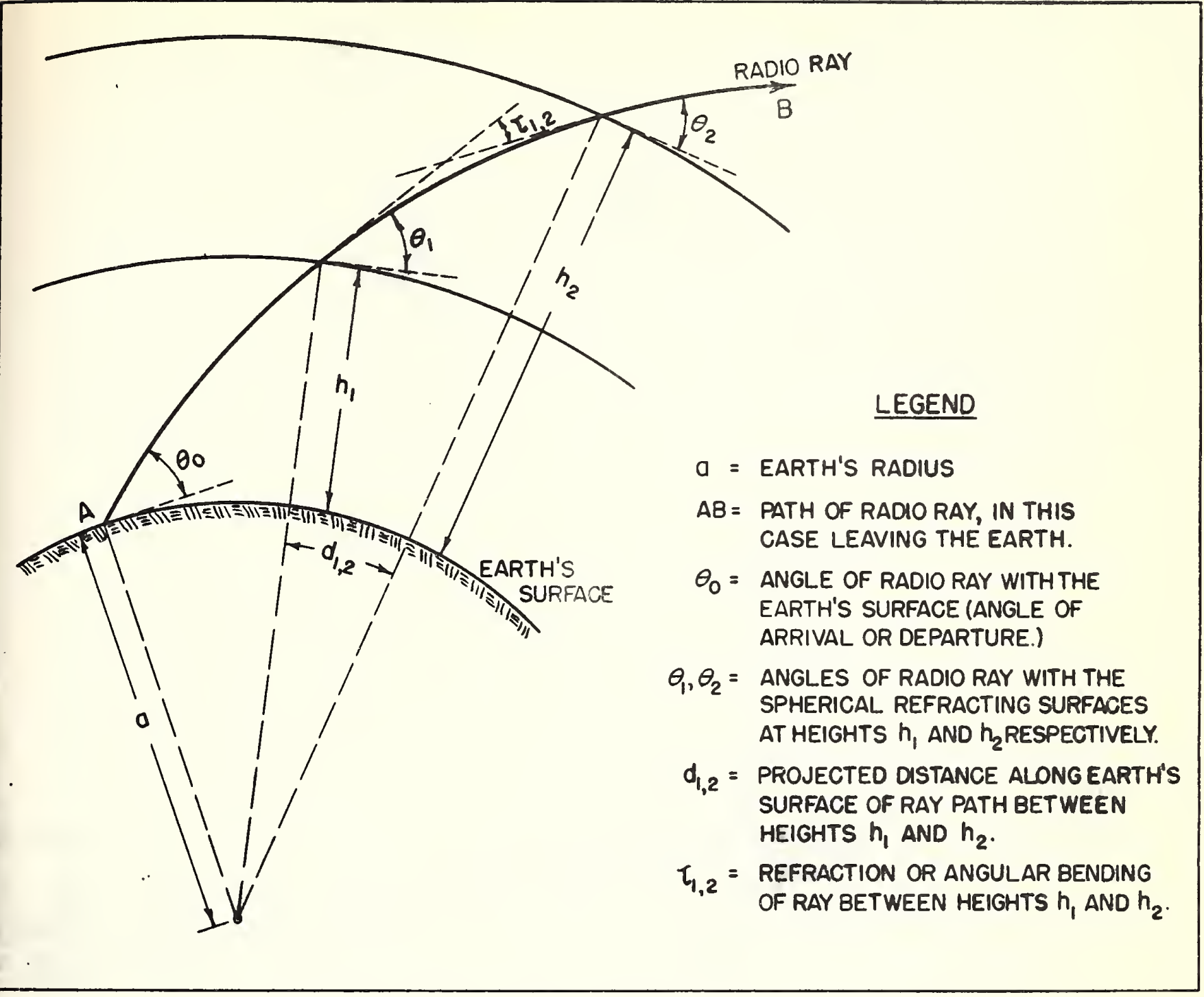

Fig. 9 REFRACTION $\tau_{1,2}$ IN THE EARTH'S ATMOSPHERE BETWEEN HEIGHTS $h_{1}$ AND $h_{2}$ 


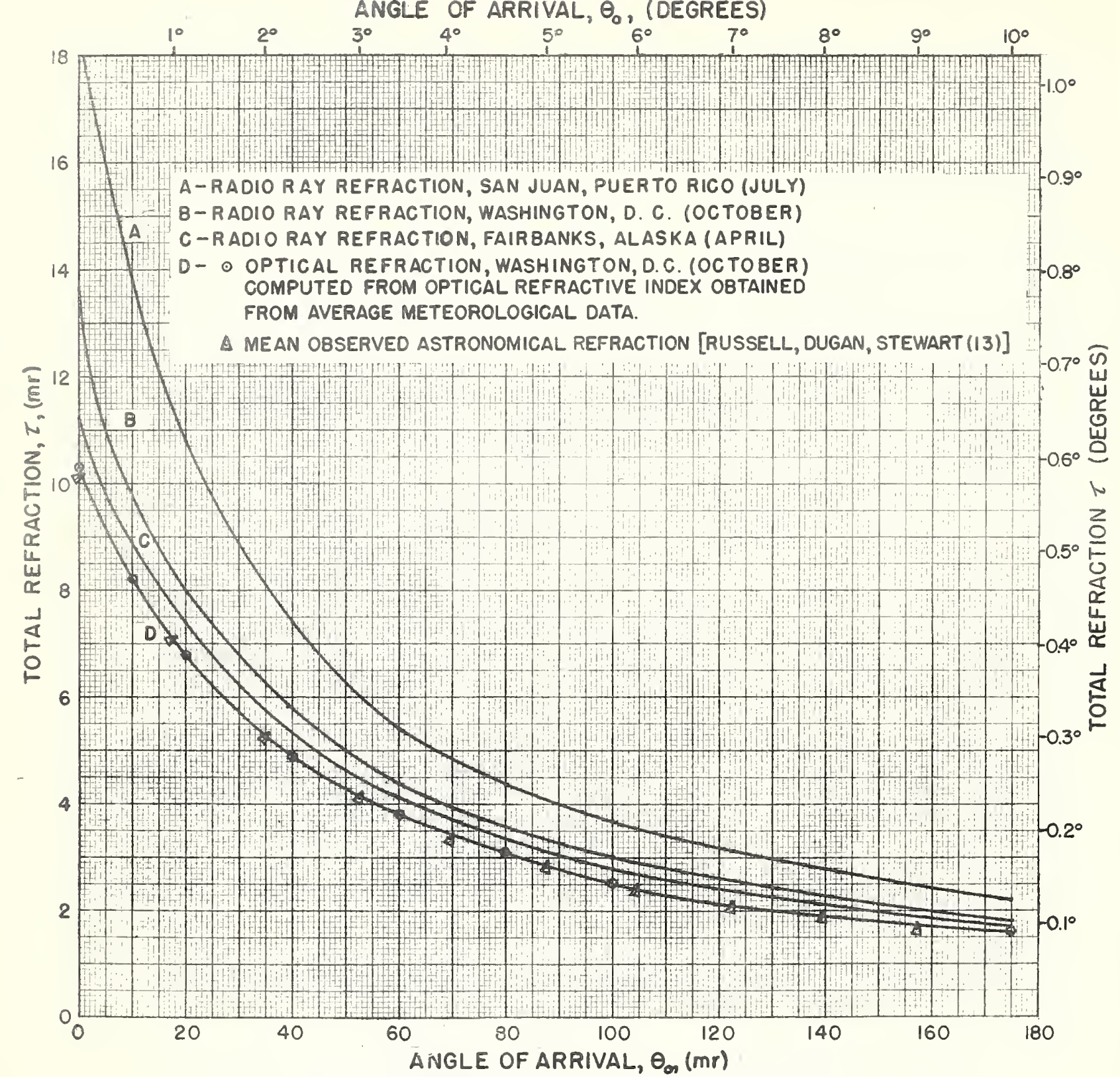

Fig. 10 TOTAL REFRACTION VS ANGLE OF ARRIVAL, $\theta_{0} \leq 10^{\circ}$ 


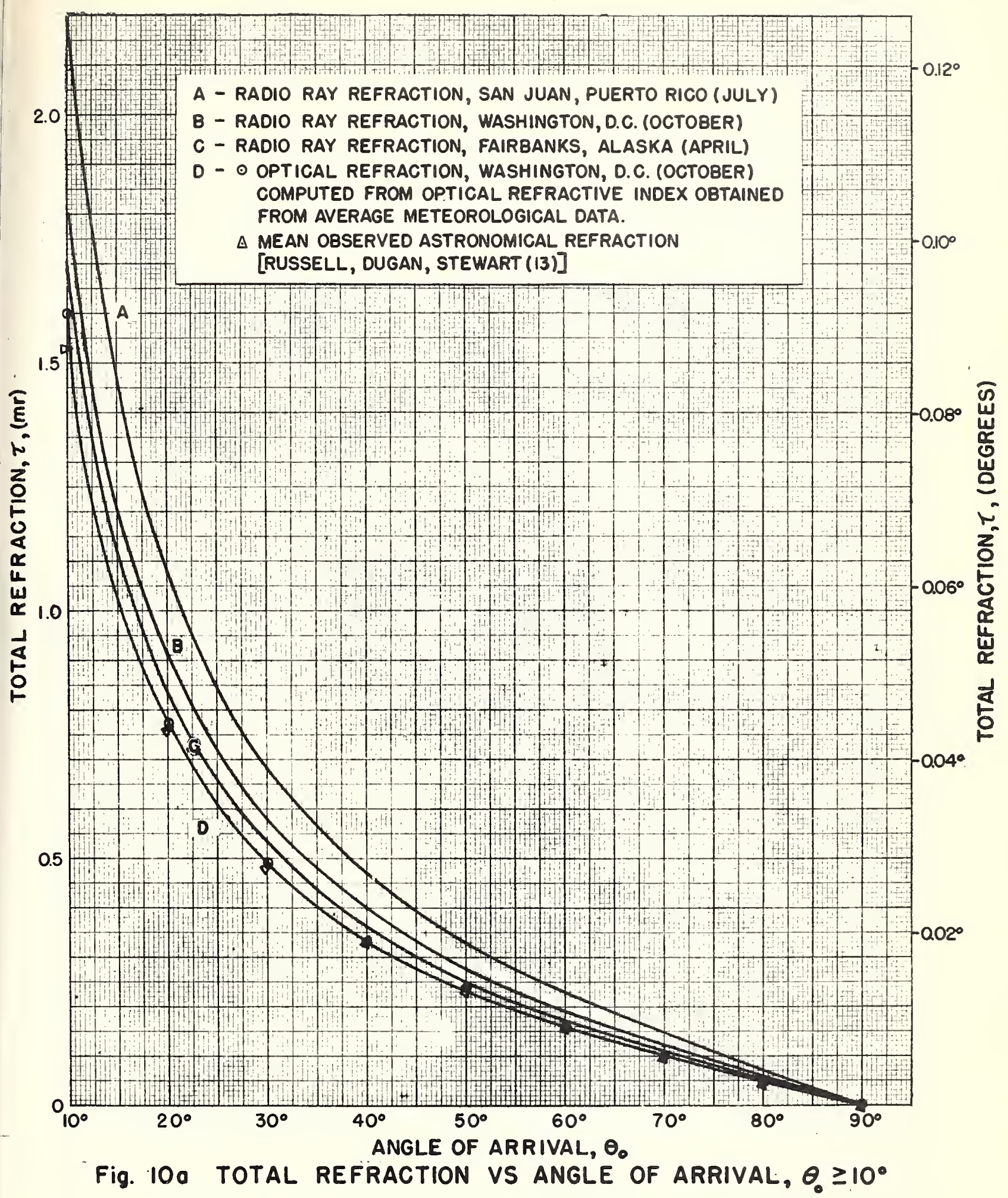




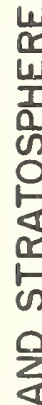

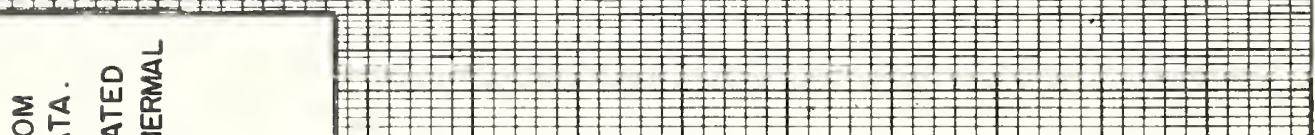

운 $\frac{1}{1}$

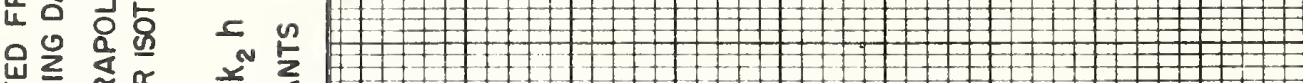

5 足皆

$\sum_{0}$ o

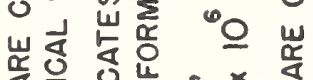

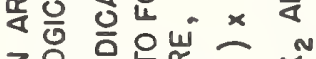

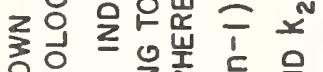

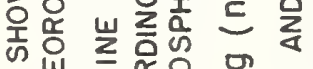

ง

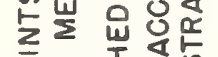

iij

$\frac{1}{a}$

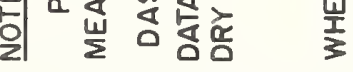

$\approx$

\%

-

4.

$=0$

$\sum 0$

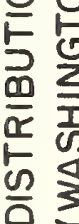

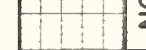

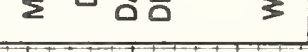




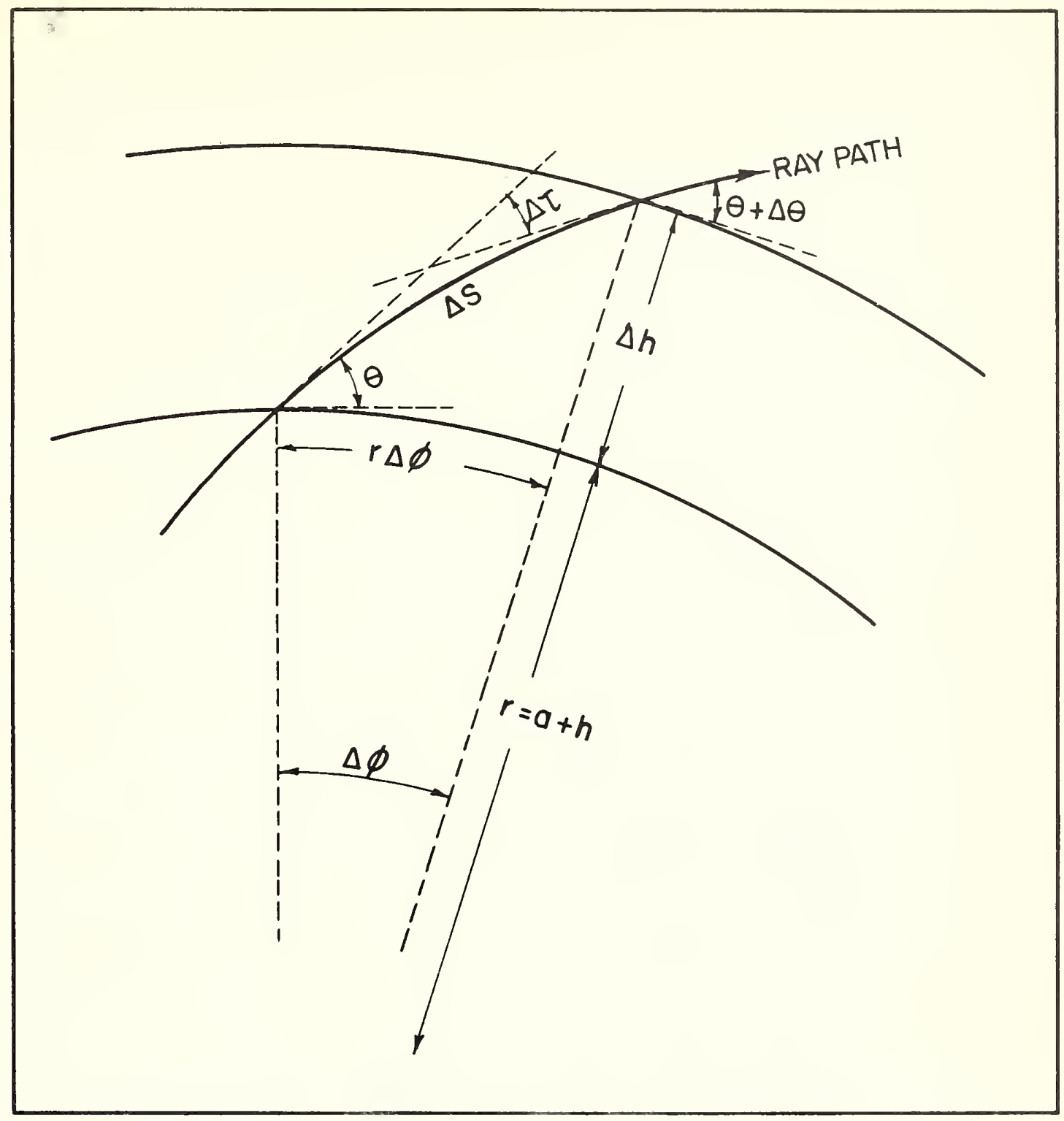

Fig.12 INFINITESIMAL SECTION OF RAY PATH 


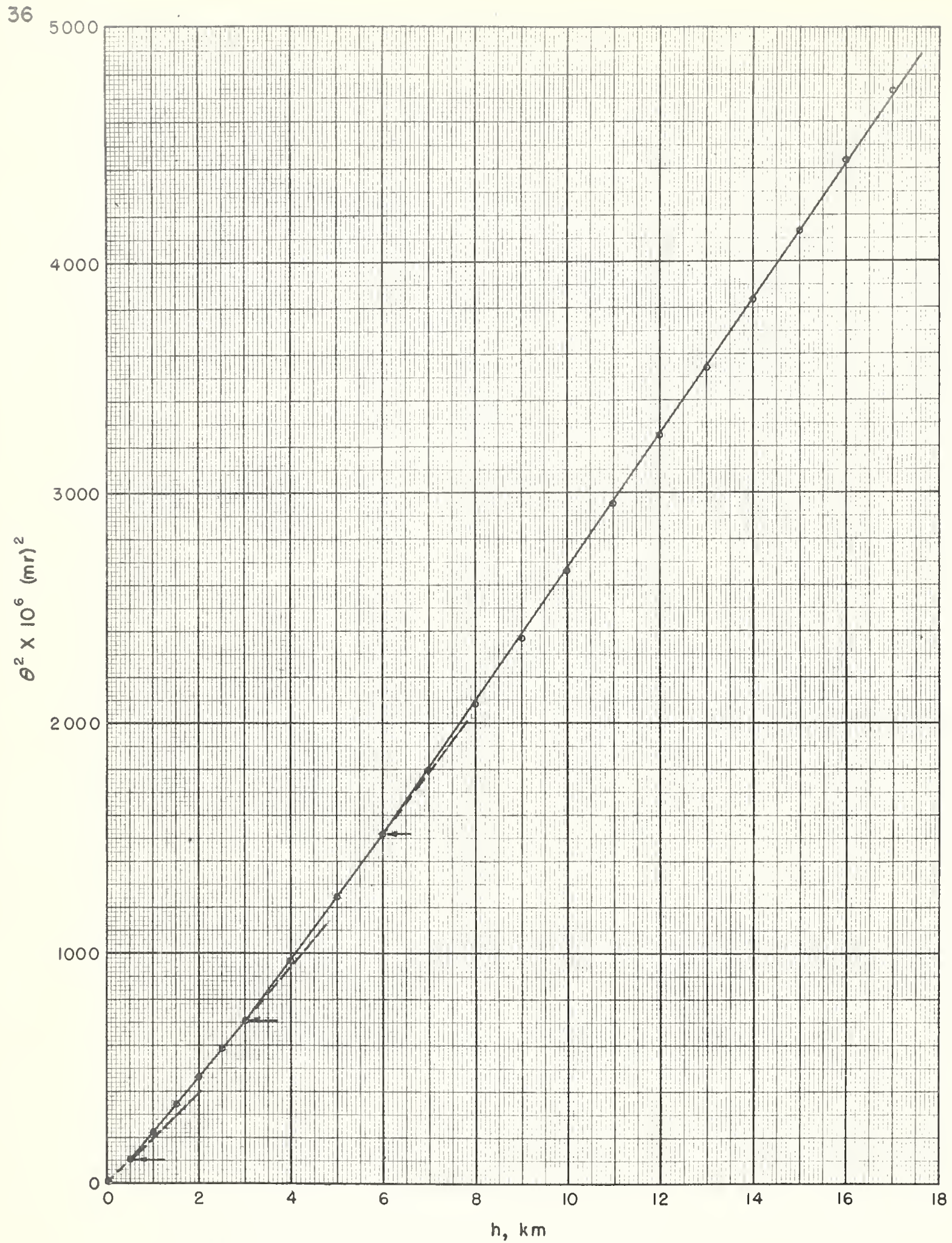

Fig. $13 \theta^{2}$ VS. HEIGHT ( $\theta$ IS THE ANGLE OF ARRIVAL AT HEIGHT $h$ ) WASHINGTON, D. C., OCTOBER, $\theta_{0}=0 \mathrm{mr}$.

$$
\theta^{2}=\theta_{0}^{2}+2\left(\Delta n+\frac{h}{a}\right)-2\left(\Delta n_{0}+\frac{h_{0}}{a}\right)
$$


